\title{
Pharmacological and Antagonistic Potentials of Mikania micrantha
}

\author{
Bikash Baral, Nabin Bhattarai and Geeta Shrestha Vaidya \\ Nepal Academy of Science and Technology (NAST), Khumaltar, Lalitpur \\ e-mail: bikubaral@yahoo.com
}

\begin{abstract}
The antimicrobial, chemical and allelopathical properties of invasive alien weed Mikania micrantha Kunth ex H.B.K were analyzed. The extraction was performed in different solvents by soxhlet extraction technique. Some bacteria (Acinetobacter sp. and Bacillus subtilis) were found to be highly inhibited, whereas the extract was found effective against Fusarium species (F. eridiforme) among the fungi. Of all the solvents used for extraction, methanolic hot extract showed good antimicrobial properties against tested pathogenic strains. The preliminary qualitative phytochemical assay divulged the presence of glycosides and quinones in the test plant. Germination rate was higher for all crops with control treatment. The germination rate decreased with the increase in the extract concentration and was found to be lowest at $5 \%$ concentration of extract. Generally, the radicle length of all bioassayed species decreased with increasing concentrations of Mikania, with Barley and Paddy being the most susceptible to the plant extract at full strength. The broad spectrum of activity of the extract indicated possibilities for wide use of $M$. micrantha for controlling the human pathogenic bacteria and phytopathogenic fungus that have been widely destroying crops.
\end{abstract}

Key words: allelopathy, germination, microbes, plant extract, ZOI

\section{Introduction}

Mikania micrantha Kunth ex H.B.K is one of the devastating invasive species belonging to family Asteraceae and is found to be growing best where fertility, organic matter, soil moisture and humidity are high enough. Because of its vigorous spreading nature, it suppresses the growth of other plants by shading light and smothering them, hence it has been named as 'Mile-a-minute" and is consistently ranked amongst the top three worst weeds of the world.

Mikania possess high allelopathic properties releasing chemicals to its surrounding that have the capacity to inhibit the growth of plants. Mikania debris incorporated into soil was found to inhibit and slow the seedling growth and germination in some crops. The extract of $M$. micrantha has a strong inhibition activity against many plant pathogens. In order to use the resource efficiently and provide theoretical basis for novel plant -derived fungicide developing, the chemical constituents, microbial activity and its allelopathic potentials has been investigated.

For centuries, plants have been continuously used as a source of medicines and the extract of plant have great potential as antimicrobial compounds against microorganisms (Gislene et al. 2000). Allelopathy plays an important role in regulating plant diversity (Chou \& Lee 1991). In the beginning most of the allelopathic research was conducted to investigate the effect of weeds on crops and one crop on another. However, at present, the allelopathic crop and weed residues are being utilized for weed control in crops. The purpose of the present study was to elucidate the biological and chemical properties of M. micrantha extracts 
against different crops along with its medicinal effects. This paper also aims to unveil the allelopathic chemicals demonstrating their growth inhibition properties on the young seedlings of the different crop plants (Maize, Barley, Wheat and Barley).

\section{Methodology}

Sampling: Harvesting of the plant species were done in August. Whole plant parts were used for the experiment. The dry plant was pulverized to powder with the aid of grinder and was extracted according to their differential polarities.

Preparation of standard culture inoculums: Eleven different clinical bacterial strains and seven phytopathogenic fungal strains were employed to test the antimicrobial potentials of the plant. Bacterial strains used for the experimentation were Klebsiella pneumoniae, Proteus mirabilis (ATCC 49132), Salmonella Typhi, Pseudomonas aeruginosa (ATCC 27853), Bacillus subtilis (ATCC 6633), Enterococcus faecali (ATCC 29212), S. Paratyphi, Acinetobacter spp., Staphylococcus aureus (ATCC 25923), Schigella dysentriae and Escherichia coli (ATCC 25922). The fungal strains employed for the experiment were F. proliferatum, F. eridiforme, F. moniliforme, Fusarium oxysporum, Exserohilium turcicum, Curvularia sp. and Sclerotium rolfsii. For bacterial inoculums, colonies were selected from 18 - $20 \mathrm{~h}$ old cultures. Turbidity was adjusted to $0.5 \mathrm{McF}$ arland standards $\left(1.5 \times 10^{8}\right.$ $\mathrm{CFU} / \mathrm{ml}$. The standard culture inoculum of each fungal strain was prepared in potato dextrose broth (PDB) and adjusted to a range of $1 \times 10^{6}-5 \times 10^{6}$ spores/ml (Aberkene et al. 2002).

Antimicrobial susceptibility testing: Antimicrobial activity was tested by agar-well diffusion method for determining the susceptibility of different bacteria and fungus to extracts of M. micrantha. The inoculums of bacteria and fungi were prepared in Nutrient Broth and Potato Dextrose broth (PDB) respectively. In-vitro spreading techniques of the respective strains were carried out in Nutrient Agar and Potato Dextrose Agar medium. The different concentrations of the extracts were prepared and poured in well of diameter $6 \mathrm{~mm}$. The different concentrations of the working solutions ( $100 \mathrm{mg} / \mathrm{ml}, 200 \mathrm{mg} / \mathrm{ml}$ and $300 \mathrm{mg} / \mathrm{ml}$ ) were prepared in DMSO (Dimethyl sulphoxide). $50 \mu \mathrm{l}$ of the respective extracts were seeded into the wells and were incubated at $27 \pm 1^{\circ} \mathrm{C}$ for bacteria ( $24 \mathrm{~h}$ ) and $37 \pm 1^{\circ} \mathrm{C}$ for fungi $(7$ d). ZOI as indicated by the clear zone i.e. without growth of organism around the well was measured. The tests were done in triplicates and mean value was taken. The solvent used for preparation of working solution was used as negative control. The zones of the solvents, if observed, were deducted from the zones of inhibition created by the crude extracts.

Phytochemical analysis: Standard phytochemical test was carried out on plant samples using method as given by Harborne (1998) to demonstrate the presence of different pharmacologically active compounds.

Allelopathical potentials: For calculating the allelopathic effect of the $M$. micrantha against other crops, the extract was prepared by imbibing the powder over night followed by filtration and evaporating in rotary evaporator. Different concentration of extract was prepared in water (10 $\mathrm{mg} / \mathrm{ml}, 20 \mathrm{mg} / \mathrm{ml}, 30 \mathrm{mg} / \mathrm{ml}, 40 \mathrm{mg} / \mathrm{ml}$ and $50 \mathrm{mg} / \mathrm{ml}$ ). Seeds of different crops were sown on a filter paper seedbed in sterilized petridishes. The filter papers were moistened with aqueous leaf extracts of the test allelopathic seeds. Control was treated similarly with distilled water. There were three replicates of each treatment with 10 seeds per Petri plate and were incubated in dark. At every three days interval, the germination percentage, roots and shoots length $(\mathrm{cm})$ were measured till nine days. On final day of the experimentation, dry weight of shoots (g) and roots (g) were measured separately. Parallely, a control set of experiment was carried out for each replications.

Statistical analysis: A complete randomized design with five replications was used for the extract studies. Experiments of aqueous extract were conducted thrice and the means of ten replicates were averaged. The obtained results were subjected to further analysis using SPSS (V.14).

\section{Results and Discussion}

The extract yield was found to be highest in the aqueous (15.9\%) followed by the methanol (4.8\%) and Acetone (2.6\%) (Fig.1). Analysis of antifungal activities against the different concentrations of the methanolic hot extract showed good inhibitory effect against $F$. moniliforme and $F$. proliferatum. 
Bikash Baral et al./Pharmacological and .....

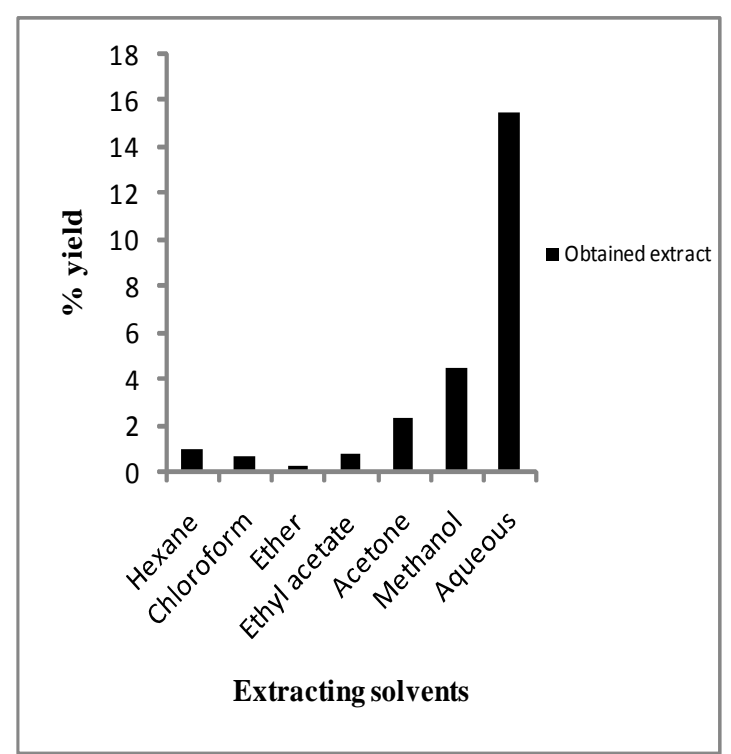

Fig. 1. Total yield of the extract using different solvents

The extract did not show any inhibitory effect against Exserohilium and Stenophylum (Fig. 2). In different solvent extraction, the extract of Mikania showed the good properties against $F$. moniliforme followed by the ether and ethyl acetate extract against $F$. eridiforme. Exserohilium turcicum was found not to

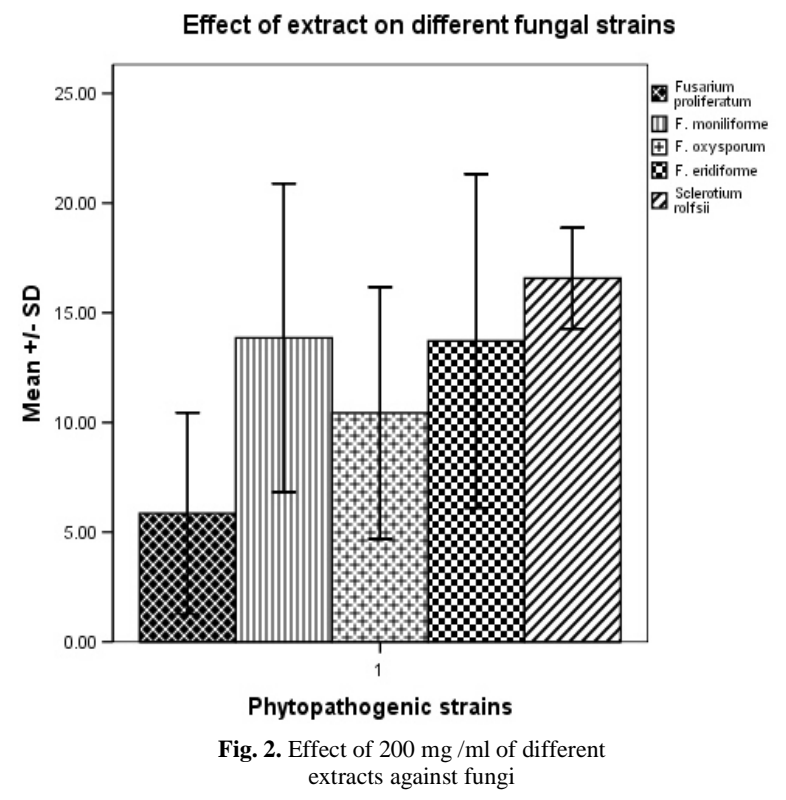

\begin{tabular}{l|c|c|c|c}
\hline \multicolumn{5}{c}{ Table 1. Antifungal properties of Methanolic extract } \\
\hline Pathogenic Fungus used & \multicolumn{5}{c}{$\begin{array}{c}\text { Methanolic Soxhlet extraction, } \\
\text { ZOI (mm) }\end{array}$} \\
& \multicolumn{5}{c}{ Conc. (mg / ml) } \\
\cline { 2 - 5 } & \multicolumn{5}{c}{$\mathbf{1 0 0}$} & $\mathbf{1 5 0}$ & $\mathbf{2 0 0}$ \\
\cline { 2 - 5 } & $\mathbf{5 0}$ & $\mathbf{1 0 0}$ & 8 & 9 \\
F. oxysporum & 6 & 8 & & \\
F. moniliforme & \multicolumn{4}{|c}{} \\
F. proliferatum & 12 & 19 & 21 & 18 \\
F. eridiforme & 7 & 13 & 13 & 15 \\
Sclerotium rolfsiii & 7 & 10 & 12 & 13 \\
Exserohilum turcicum & - & - & 13 & 9 \\
Stenophylum sp & - & - & - & - \\
& - & - & - & -
\end{tabular}

Values are an average of three replicates

"-": No inhibition

be inhibited by any concentration of the different extracts (Table 2). Bacillus subtilis, Acinetobacter sp. and $S$. Typhi were found to be greatly inhibited by the different extracts fraction Fig, 3. Some of the tested bacteria were found not to be inhibited by the different concentrations of the obtained extract fractions (Table 3) Fig. 5.

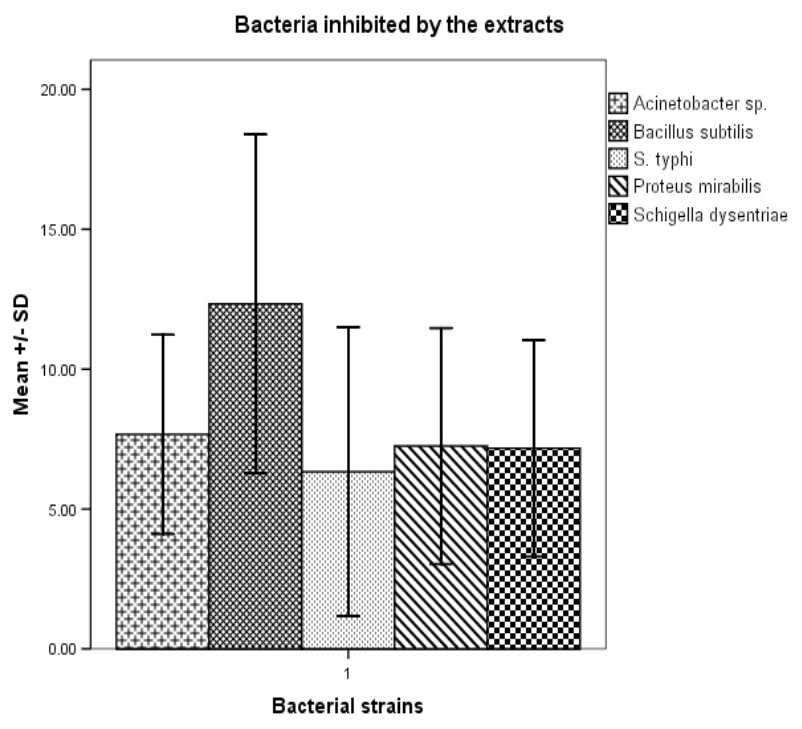

Fig. 3. Effect of $100 \mathrm{mg} / \mathrm{ml}$ of different extracts against bacteria 
Nepal Journal of Science and Technology 12 (2011) 75-84

Table 2. Antifungal properties showing the ZOI of different extracts obtained by soxhlet method

\begin{tabular}{lcc|c|c|c|c|c}
\hline Pathogenic & \multicolumn{7}{c}{ Zone of inhibition (ZOI, mm, 100 mg / ml of extracts) } \\
\hline fungus & Hexane & Chloroform & Ether & Ethyl acetate & Acetone & Methanol & Aqueous \\
\hline & & & & & & & \\
F. eridiforme & 16 & 18 & 21 & 21 & 9 & 11 & NI \\
F. moniliforme & NI & 14 & 13 & 14 & 14 & 22 & 20 \\
F. oxysporum & NI & 7 & 11 & 10 & 12 & 16 & 17 \\
F. proliferatum & NI & NI & NI & NI & 7 & 13 & 8 \\
S. rolfsii & 15 & 17 & 21 & 17 & 17 & 14 & 15 \\
E. turcicum & NI & NI & NI & NI & NI & NI & NI \\
\hline
\end{tabular}

Values are an average of three replicates; "NI": No inhibition

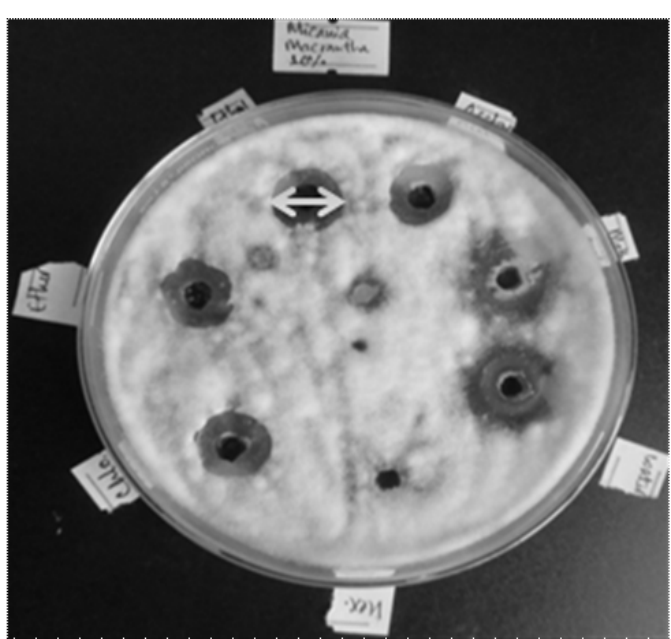

ZOI of F. moniliforme

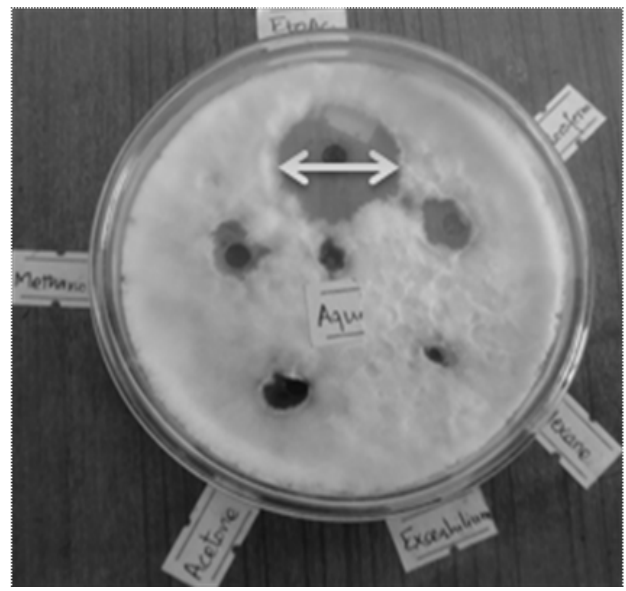

Exserhilium sp. against Mikania extracts

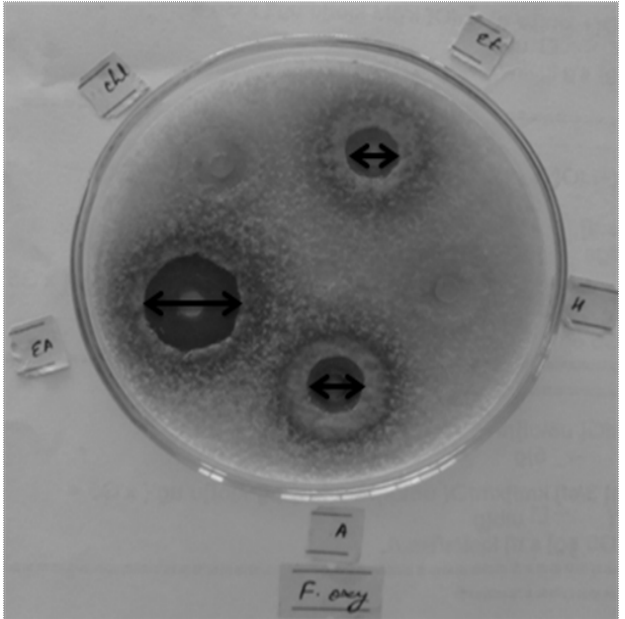

ZOI of F. oxysporum

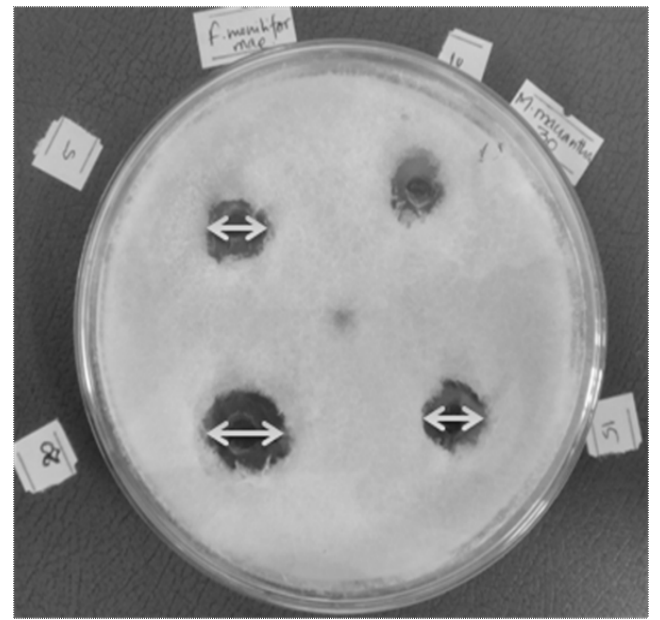

Methanolic extract against F. moniliforme

Note: arrows indicate the diameter of the zone of inhibition

Fig. 5. Demonstration of the antimicrobial properties by extract against different organisms 
Bikash Baral et al./Pharmacological and .....

Table 3. Antibacterial properties showing the ZOI of different extracts obtained by soxhlet method

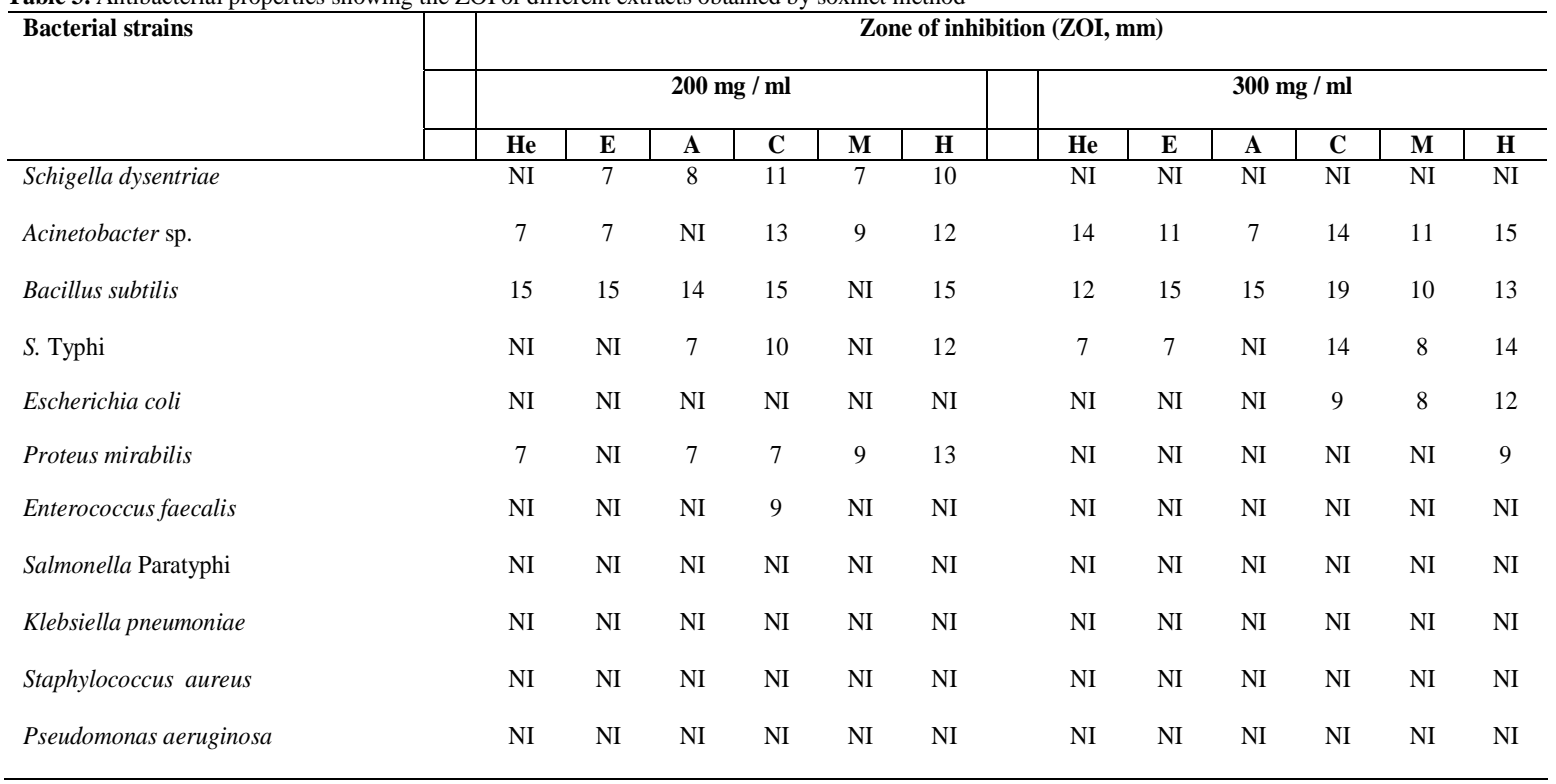

Note: He: Hexane; E: Ethyl acetate; A: Acetone; C: Chloroform; M: Methanol; H: Aqueous; "NI": No inhibition

Values are an average of three replicates

The extracts of the plant shows the presence of Glycosides and Quinones. These compounds are known to be biologically active and therefore aid the antimicrobial activities of Mikania. These secondary metabolites exert antimicrobial activity through different mechanisms.

Germination rate was higher for all crops in control treatments. The germination rate decreased with the increase in the extract concentration and was found to be lowest at five percent concentration of extract. None of the paddy germinated at any treatment with extract at three days Fig. 4 (Table 4). Similarly, the weight of roots and shoots were highest for Maize on control treatment followed by the Paddy (Table 5). Shoot length and root length were found to be highest in wheat followed by the maize at nine days. The growth of the shoot and the roots of the paddy was found to be lowest, it means that the extract have the maximum allelopathic effect on the growth of the paddy seeds followed by Barley. Comparatively, the length of the roots was found to be longer than that of the shoots. In sharp contrast, the shoot of wheat was found to be greater than the roots. Generally, the radicle length of all bioassay species decreased with increasing concentrations of Mikania plant extract, with Barley and Paddy being the most susceptible to the root extract at full strength (Table 6, 7 \& 8).

\begin{tabular}{|c|c|c|c|c|c|}
\hline \multirow{2}{*}{$\begin{array}{l}\text { Seeds of } \\
\text { different } \\
\text { crops }\end{array}$} & \multicolumn{5}{|c|}{ M. micrantha extract's effect on seeds germination of different crops } \\
\hline & $1 \%$ & $2 \%$ & $3 \%$ & $4 \%$ & $5 \%$ \\
\hline Maize & & & & & \\
\hline Wheat & & & & & \\
\hline
\end{tabular}

Fig. 4. Photo plates showing the allelopathical properties on different crop plants 
Table 4. Germination of different plant species in the presence of the extract of Mikania (\%) at 3 days

\begin{tabular}{|c|c|c|c|c|}
\hline \multirow{3}{*}{$\begin{array}{l}\text { Treatments (Extracts } \\
\text { conc.) }\end{array}$} & \multicolumn{4}{|c|}{ Germination (\%)* } \\
\hline & \multicolumn{4}{|c|}{ Seeds of the crop used } \\
\hline & Maize & Wheat & Barley & Paddy \\
\hline Control & 80 & 70 & 90 & 60 \\
\hline $1 \%$ & 90 & 90 & 90 & N/A \\
\hline $2 \%$ & 90 & 90 & 60 & N/A \\
\hline $3 \%$ & 90 & 80 & 70 & N/A \\
\hline $4 \%$ & 80 & 80 & 60 & N/A \\
\hline $5 \%$ & 70 & 70 & 20 & N/A \\
\hline
\end{tabular}

N/A: No germination,

$* \bar{x}(n=10)$

Table 5. Weight of shoots and roots at $9 \mathrm{~d}$ (in g)

\begin{tabular}{lc|c|c|c|c|cc}
\hline Plants & $\begin{array}{c}\text { Plant } \\
\text { parts }\end{array}$ & \multicolumn{7}{c}{ Concentrations of crude extract (\%)* } \\
\hline & used & $\mathbf{1}$ & $\mathbf{2}$ & $\mathbf{3}$ & $\mathbf{4}$ & $\mathbf{5}$ & Control \\
\hline Maize & Shoots & $0.0388 \pm 0.06$ & $0.0305 \pm 0.16$ & $0.0289 \pm 0.07$ & $0.0195 \pm 0.02$ & $0.0171 \pm 0.24$ & $0.0434 \pm 0.34$ \\
& Roots & $0.0352 \pm 0.006$ & $0.04 \pm 0.18$ & $0.0329 \pm 0.064$ & $0.0298 \pm 0.04$ & $0.0034 \pm 0.36$ & $0.0401 \pm 0.15$ \\
\multirow{3}{*}{ Barley } & Shoots & $0.0174 \pm 0.61$ & $0.012 \pm 0.08$ & $0.0005 \pm 0.31$ & $0.002 \pm 0.06$ & $0.001 \pm 0.11$ & $0.0193 \pm 0.22$ \\
& Roots & $0.0016 \pm 0.21$ & $0.0013 \pm 0.19$ & $0.0009 \pm 0.20$ & $0.0004 \pm 0.34$ & $0.0004 \pm 0.38$ & $0.0092 \pm 0.20$ \\
Wheat & Shoots & $0.0169 \pm 0.18$ & $0.0131 \pm 0.22$ & $0.0106 \pm 0.35$ & $0.009 \pm 0.26$ & $0.0058 \pm 0.11$ & $0.0188 \pm 0.42$ \\
& Roots & $0.0124 \pm 0.24$ & $0.0082 \pm 0.26$ & $0.0049 \pm 0.41$ & $0.0033 \pm 0.34$ & $0.0018 \pm 0.29$ & $0.0178 \pm 0.24$ \\
Paddy & Shoots & $0.0266 \pm 0.33$ & $0.0085 \pm 0.31$ & $0.003 \pm 0.20$ & $0.0026 \pm 0.35$ & $0.0007 \pm 0.45$ & $0.0292 \pm 0.41$ \\
& Roots & $0.0062 \pm 0.27$ & $0.0027 \pm 0.25$ & $0.0014 \pm 0.34$ & $0.0005 \pm 0.53$ & $0.0003 \pm 0.17$ & $0.0139 \pm 0.35$ \\
\hline
\end{tabular}

$* \bar{x} \pm S D(n=10)$

Table 6. Average length of Shoots and Roots at $3 \mathrm{~d}$ by different extract concentrations

\begin{tabular}{|c|c|c|c|c|c|}
\hline \multirow[t]{2}{*}{ Parameters } & \multirow{2}{*}{$\begin{array}{c}\text { Extract conc. } \\
(\%)\end{array}$} & \multicolumn{4}{|c|}{ Tested crops * } \\
\hline & & Maize & Barley & Paddy & Wheat \\
\hline \multirow{6}{*}{$\begin{array}{l}\text { Shoots length } \\
\text { (cm) }\end{array}$} & 1 & $1.06 \pm 0.78$ & $0.8 \pm 0.65$ & NG & $2.53 \pm 0.04$ \\
\hline & 2 & $0.94 \pm 0.90$ & NG & NG & $1.77 \pm 0.79$ \\
\hline & 3 & $0.95 \pm 0.80$ & $0.35 \pm 0.56$ & NG & $1.29 \pm 0.25$ \\
\hline & 4 & $0.51 \pm 0.52$ & NG & NG & $0.88 \pm 0.54$ \\
\hline & 5 & $0.61 \pm 0.54$ & NG & NG & $0.56 \pm 0.52$ \\
\hline & Control & $1.02 \pm 0.83$ & $2.56 \pm 0.14$ & $0.92 \pm 0.81$ & $3.04 \pm 0.25$ \\
\hline \multirow{6}{*}{$\begin{array}{l}\text { Roots length } \\
(\mathrm{cm})\end{array}$} & 1 & $3.14 \pm 0.95$ & $1.21 \pm 0.75$ & NG & $3.50 \pm 0.33$ \\
\hline & 2 & $3.53 \pm 0.04$ & $0.15 \pm 0.21$ & NG & $2.12 \pm 0.96$ \\
\hline & 3 & $3.16 \pm 0.07$ & $0.36 \pm 0.34$ & NG & $1.23 \pm 0.99$ \\
\hline & 4 & $1.82 \pm 0.19$ & $0.09 \pm 0.13$ & NG & $1.05 \pm 0.69$ \\
\hline & 5 & $0.95 \pm 0.89$ & $0.03 \pm 0.06$ & NG & $0.90 \pm 0.78$ \\
\hline & Control & $2.96 \pm 0.17$ & $6.06 \pm 0.26$ & $0.43 \pm 0.45$ & $5.01 \pm 0.64$ \\
\hline
\end{tabular}

"NG": No germination

$* x \pm S D(n=10)$ 
Bikash Baral et al./Pharmacological and .....

Table 7. Average length of Shoots and Roots at $6 \mathrm{~d}$ by different extract concentrations

\begin{tabular}{l|c|c|c|c|c}
\hline Parameters & $\begin{array}{c}\text { Extract conc. } \\
\text { (\%) }\end{array}$ & Maize* & Barley* & Paddy* & Wheat* \\
\hline & 1 & $5.86 \pm 0.49$ & $4.20 \pm 0.17$ & $1.51 \pm 0.03$ & $9.81 \pm 0.64$ \\
Shoots length (cm) & 2 & $5.96 \pm 0.78$ & $0.88 \pm 0.48$ & $0.51 \pm 0.51$ & $7.06 \pm 0.44$ \\
& 3 & $3.83 \pm 0.17$ & $1.99 \pm 0.84$ & $1.16 \pm 0.59$ & $5.35 \pm 0.45$ \\
& 4 & $4.59 \pm 0.22$ & $0.73 \pm 0.17$ & $0.40 \pm 0.46$ & $2.82 \pm 0.00$ \\
& 5 & $3.79 \pm 0.29$ & $0.74 \pm 0.15$ & $0.34 \pm 0.33$ & $1.91 \pm 0.74$ \\
& Control & $6.59 \pm 0.14$ & $2.40 \pm 0.94$ & $1.74 \pm 0.28$ & $8.92 \pm 0.79$ \\
& 1 & $10.93 \pm 0.17$ & $4.35 \pm 0.96$ & $2.62 \pm 0.06$ & $6.84 \pm 0.03$ \\
Roots length (cm) & 2 & $10.81 \pm 0.31$ & $0.75 \pm 0.12$ & $0.14 \pm 0.18$ & $3.22 \pm 0.53$ \\
& 3 & $8.88 \pm 0.30$ & $1.33 \pm 0.19$ & $0.64 \pm 0.48$ & $1.66 \pm 0.43$ \\
& 4 & $5.45 \pm 0.67$ & $0.16 \pm 0.28$ & $0.09 \pm 0.15$ & $1.34 \pm 0.97$ \\
& 5 & $3.68 \pm 0.17$ & $0.24 \pm 0.33$ & NG & $1.14 \pm 0.30$ \\
& Control & $12.93 \pm 0.11$ & $5.29 \pm 0.27$ & $3.12 \pm 0.49$ & $11.34 \pm 0.51$ \\
\hline
\end{tabular}

"NG": No germination

$* \bar{x} \pm S D(n=10)$

Table 8. Average length of Shoots and Roots at $9 \mathrm{~d}$ by different extract concentrations

\begin{tabular}{lccccc}
\hline Parameters & $\begin{array}{c}\text { Extract conc. } \\
\text { (\%) }\end{array}$ & Maize* & Barley* & Paddy* & Wheat* \\
\hline Shoots length & 1 & $8.23 \pm 0.77$ & $4.28 \pm 0.08$ & $2.92 \pm 0.44$ & $13.41 \pm 0.86$ \\
(cm) & 2 & $10.68 \pm 0.97$ & $1.95 \pm 0.85$ & $2.73 \pm 0.13$ & $10.03 \pm 0.10$ \\
& 3 & $7.65 \pm 0.81$ & $2.27 \pm 0.12$ & $2.05 \pm 0.97$ & $8.34 \pm 0.57$ \\
& 4 & $5.29 \pm 0.81$ & $1.21 \pm 0.62$ & $1.30 \pm 0.49$ & $6.06 \pm 0.95$ \\
& 5 & $4.54 \pm 0.55$ & $0.82 \pm 0.32$ & $0.77 \pm 0.58$ & $4.17 \pm 0.06$ \\
& Control & $8.28 \pm 0.76$ & $3.00 \pm 0.47$ & $3.00 \pm 0.45$ & $12.14 \pm 0.69$ \\
Roots length (cm) & 1 & $10.46 \pm 0.23$ & $3.74 \pm 0.94$ & $2.96 \pm 0.59$ & $8.34 \pm 0.45$ \\
& 2 & $14.02 \pm 0.79$ & $1.36 \pm 0.32$ & $2.70 \pm 0.48$ & $3.35 \pm 0.77$ \\
& 3 & $11.74 \pm 0.09$ & $0.95 \pm 0.89$ & $1.28 \pm 0.75$ & $1.78 \pm 0.31$ \\
& 4 & $6.88 \pm 0.64$ & $0.47 \pm 0.63$ & $0.46 \pm 0.26$ & $2.10 \pm 0.24$ \\
& 5 & $4.37 \pm 0.79$ & $0.25 \pm 0.40$ & $0.19 \pm 0.11$ & $1.04 \pm 0.99$ \\
& Control & $12.97 \pm 0.39$ & $6.21 \pm 0.70$ & $4.13 \pm 0.87$ & $15.7 \pm 9.01$ \\
\hline
\end{tabular}

$* \bar{x} \pm S D(n=10)$

A large number of plants possess antimicrobial activity and some active components of them have become a potential source of new anti-infective agents against the different bacterial and the fungal strains. Plant offers a large range of natural compounds belonging to diffeent molecular families which have the various properties to humans. These molecules possess interesting biological activities which attracted several researchers to their elucidation to provide knowledge that will lead to advancement medicine. Plants may be considered as a famous chemical factory for the biosynthesis of a huge array of secondary metabolites. Many of these chemicals are utilized as medicines, scents, dyes and pesticides and are of commercial importance.

It is known that, in general, the Gram -negative bacteria are most resistant than the Gram-positive ones, however, the study showed that some of the Gramnegative organisms used in this study were found to be sensitive to the high concentration of the extract. Nevertheless, E. coli, which is a Gram-negative bacterium, was also inhibited by the plant extract.

Bacilli causes an array of infections from ear infections to meningitis, and urinary tract infection to septicemia. Mostly they occur as secondary infections in immunodeficient hosts or otherwise compromised 
hosts. They may exacerbate previous infection by producing tissue-damaging toxins or metabolites that interfere with treatment. By the use of the Mikania plant extract, these sorts of infections to the humans body can be reduced to a considerable level. On the other hand, Acinetobacter causes pneumonia, skin and wound infections, urinary tract infections and blood infections. Blood-stream infections caused by Acinetobacter tend to be most severe. Application of the Mikania extract on such type of diseases helps them to reduce to a normal level.

Fusarium sp. are basically the most devastating diseases of all, that attacks both the humans and the plants. Extracts of Mikania are found to be strong inhibitor for the growth of the Fusarium sp., which indicates its inhibitory and preventory revolution against the deadly diseases. F. moniliforme is responsible for the stalk rot, that may work alone or in combination with others. Stalks rot may cause premature dying of plants, chaffy kernels and poor filling of ears at tips. Application of the Mikania extract helps in the elimination of the disease, thereby preventing the premature dying of stalks.

The broad activity of the extracts explains the widespread use of this plant for wound healing and other applications. Significant reductions in the germination and growth of the roots and shoots were observed as the extract concentration increased. This preliminary research suggests that $M$. micrantha contains potent allelochemicals that enhances its efficiency as a weed. On the other hand, residues or aqueous extracts of the plant may be useful for the different types of weed management.

In the germination of the crops seeds in the different concentrations of the extract, it was observed that the increase in the extract concentration have the inhibitory effect of the plants seed. Higher is the concentration of the extract, lower is the germination of the seeds and vice-versa. In the control treatment, the growth of the crops seedlings were found to be high than others. The growth's rate was found in the increasing order of Paddy, Barley, Wheat and Maize.

The experiments described here provide evidence of the existence of inhibitory factors in Mikania which can influence germination and growth of certain crop species. The tested species showed different responses to Mikania extract. Results of these studies suggest that Mikania has an allelopathic influence on other plants in addition to its competitive ability, as reported previously by Wong (1964). Verification rests both on isolation of one or more active compounds from plants and on evidence that they exists and act in the soil system.

The experiments described here provide evidence of the existence of inhibitory factors in Mikania which can influence germination and growth of certain weed species. The test species showed different responses to Mikania extract differently to the germination of the different crop plants. Quantities of allelochemicals vary between different plant tissues, and under different phenological and environmental conditions (Putnam \& Duke 1978, Rice 1984). The magnitude of allelopathic interactions is also dependent upon the concentration and chemical stability of the active compounds as well as upon plant tolerance to such compounds and their microbial metabolites (Phillips et al. 1980). Thus, accurately characterizing allelopathy and its relative impact can be difficult unless such aspects are taken into account. Identification of the compounds responsible for the effects observed in these studies would further define this probable allelopathic interaction.

These days the focus on chemical interactions between plant and other organisms has been done, which is mediated by secondary plant metabolites. Induced chemical defense in plant, plant chemical communication, relationships between secondary plant metabolites and evolution has been tremendously increased.

\section{Acknowledgements}

We would like to thank Krishna Giri and Bijaya Laxmi Maharjan for helping with the statistical and phytochemical analysis. Heartly thanks to Mukesh Ghimire for providing the plant samples. Thanks are also to the NAST for providing research facilities.

\section{References}

Aberkene, A., M. Cuenca-Estrella., A. Gomez-Lopez., E. Petrikkou., E. Mellado., A. Monzon., J.L. RodriguezTudela and the Eurofung Network. 2002. Comparative evaluation of two different methods of inoculum 
preparation for antifungal susceptibility testing of filamentous fungi. Journal of Antimicrobial Chemotherapy, 50(5): 719-722.

Ashrafi, Z., H. R. Mashhadi and S. Sadeghi. 2007. Allelopathic Effects of Barley (Hordeum vulgare) on Germination and Growth of Wild Barley (Hordeum spontaneum). Pak. J. Weed Sci. Res. 13 (1-2): 99-112.

Caussanel, J. P. 1979. Non-competitive effects between lamb's quarters (Chenopodium album L.) and maize (INRA 258). Weed Research, 19: 123-135.

Chour, C. H. and Y. F. Lee. 1991. Allelopathic dominance of Miscanthus transnorrisonensis in an alpine grassland community in Taiwan. J. Chem. Ecol. 17: 2267-2281.

Chung, I. M and D. A. Miller. 1995. Natural herbicide potential and alfalfa residue on selected weed species. Agronomy Journal, 87: 920-925.

Gislene, G. F. N., J. Locatelli., P. C. Freitas and G. L. Silva. 2000. Antibacterial activity of plant extracts and phytochemicals on antibiotic resistant bacteria. Brazilian Journal of Microbiology, 31: 247-256.

Harborne, J. B. 1998. Phytochemical Methods: A Guide to Modern Techniques of Plant Analysis. (3rd edition). Chapman and Hall Co., New York, pp.1-302.

Inderjit. 1996. Plant phenolics in allelopathy. Botanical Review, 62:186-202.

Mahall, B. E. and R. M. Callaway. 1991. Root communication among desert shrubs. In: Proceedings of the National Academy of Science of the United States of America, 88: 874-876.

May, F. E. and J. E. Ash. 1990. An assessment of the allelopathic potential of Eucalyptus. Australian Journal of Botany, 38:245-254.
Phillips, R. E., R. L. Blevins., G. W. Thomas., W. W. Frye and S. H. Phillips. 1980. No-tillage agriculture. Science, 208(4448): 1108-1113.

Putnam, A. R. and C. Tang. 1986. The Science of Allelopathy. John Wiley \& Sons, New York, USA.

Putnam, A. R. and W. B. Duke. 1978. Allelopathy in agroecosystems. Ann. Rev. Phytopathol., 16: 431-451.

Rice, E. L. 1984. Allelopathy ( $\left.2^{\text {nd }} E d n\right)$, Academic Press, Orlando, pp.422.

Rios, J. L and M. C. Recio. 2005. Medicinal plants and antimicrobial activity. Journal of Ethnopharmacology, 100: $80-84$.

Tawaha, A. M. and M. A. Turk. 2003. Allelopathic effects of black mustard (Brassica nigra) on germination and growth of wild barley (Hordeum sponataneum). J. Agron. Crop Sci. 189: 298-303.

Tomoko N., A. Takashi., T. Hiromu., I. Yuka., M. Hiroko., I. Munekazu., T. Totshiyuki., I. Tetsuro., A. Fujio., I. Iriya., N. Tsutomu and W. Kazuhito. 2002. Antibacterial activity of extract prepared form tropical and subtropical plants on methicillin-resistant Staphylococcus aureus. J. Health Sci., 48: 273-276.

WHO. 2002. Traditional Medicine: Growing needs and Potential. WHO Policy perspectives on Medicines. World Health Organization, Geneva pp. 1-6.

Wong, R. 1964. Evidence for the presence of growth inhibitory substances in Mikania cordata (Burn. F.) B. L. Robinson. J. Rubber Research Institute of Malaya, 18: 231-242. 
Nepal Journal of Science and Technology 12 (2011) 75-84 